\title{
Land Use Decisions and Site Selection: a GIS-based Method
}

\author{
S. M. VEITCH \\ Bureau of Resource Sciences \\ PO Box E11 Kingston ACT 2604 \\ AUSTRALIA
}

\begin{abstract}
A geographic information system is configured with a graphical user interface to enable the integration of expert analysis with public perceptions of information in a scenario based decision framework. The system, ASSESS - A System for SElecting Suitable Sites, requires clear problem definition to establish decision variables (criteria) which are addressed by: thematic data selection, interpretation of theme attributes to assign rating values; and arithmetic combination to generate scenarios.

GIS functionality is used to capture data, establish spatial alignment between themes and to rasterise all vector data. Theme based attribute tables are reviewed by experts to define initial sets of suitability ratings. System users then select themes and adjust ratings to represent their own knowledge and/or attitude assessments as decision scenarios. The system objective is to apply a selection sieve to identify areas with a high likelihood of satisfying site suitability and land use decision needs, in contrast to a quantitative analysis with its aim of an optimised outcome.

The system is fast, scalable from whole continents to small regions and provides a transparent, defensible and versatile decision support environment. The method's application is outlined for site selection for radioactive waste disposal.
\end{abstract}

\section{Keywords}

Land use decisions, site selection, radioaclive waste, optimisation, ASSESS, GIS

\section{INTRODUCTION}

A wide range of aesthetic, economic and ecological values are attached to natural resources by society (McHarg 1969, Richards 1992, Brown and MacLeod, 1996) and a complex and potentially conflicting mix of these values complicates decisions on how resources should be used or reallocated for a land use (Richards 1992). The ability to integrate and simultaneously assess biophysical, economic and social components of systems with inclusion of the user as a surrogate for society is increasingly recognised as necessary for effective land use decision making (Gault et al. 1987, Richards 1992, Watson and Wadsworth 1996).

Modelling techniques favoured by many disciplines are being implemented using GIS, both as a spatial and as a modelling engine (Battey and Xie 1994).When 
linked with a graphical user interface, the GIS also enables the representation of, and access to, knowledge bases and decision frameworks (Srinivasan and Richards 1992, Stein et al. 1995).

Integration of the user in decision support systems is assisted by techniques that assist the user by directing its use for a goal without preventing the exploration of system intricacies as the user's knowledge of the system and its components develops. As such, "a DSS should be process independent, and user driven or controlled" (Sprague 1986).

\section{ASSESS: SITE SELECTION WITHOUT OPTIMISATION}

ASSESS - A System for SElecting Suitable Sites is a GIS-based modelling strategy configured to provide a flexible decision support system. It uses both quantitative and qualitative data and formalises a process to interpret and render categories of consequence to a decision task. ASSESS incorporates a graphics window for spatial display and menu panels for site selection and land use decision functions. It features easy to access GIS functionality, on-line documentation and metadata, and a rapid scenario development operation that encourages alternative decisions and data treatments to be trialed.

In its simplest operation, ASSESS is a GIS-based implementation of the ordinal combination method (Hopkins 1977) as applied by McHarg (1969). McHarg's approach, before GIS, was to overlay transparent film maps of physical, biological or social information so that a relative indication of social value was obtained. The overlay of several maps resulted in a spatial distribution of low and high social cost areas based on a multi-criterion assessment. In ASSESS the same process is implemented but with the option for interactive rating changes and the choice of the dataset suite for analysis. ASSESS incorporates the simplicity of an ordinal combination method with the option of applying rules of combination and hierarchical combination described by Hopkins (1977). It is a sieving approach using multi-attribute techniques for compensatory, additive, multi-criteria decision making (Jankowski 1995). The difference with ASSESS is that no optimal solution is posed but through many experiments (scenarios), those areas with a consistently high suitability are indicated as worthy of closer inspection.

By not seeking a modelled optimum for a perceived best outcome the modelling process is not overdetermined (Gault et al. 1987) and the data used are not pushed to the limits of their spatial or logical accuracy. In having a scenario approach, the user is able to investigate the sensitivities of data mix and interpretation differences. In this manner interdependencies, sensitivities and redundant information is revealed but not quantified. Users from different philosophical backgrounds can use ASSESS to see a decision outcome from their own or other's viewpoints where decision tensions are rendered both spatially and by issue.

ASSESS implements the general model of MCDM (Jankowski 1995) by:

1. Problem definition - formulation of project objectives identifying the decision needs. 
2. Identification of decision variables as criteria from which issues affecting decisions are extracted.

3. Assembling for each issue, spatial information as topologically structured theme layers in GIS.

4. Interpreting theme attributes to establish a simple set of relative rating categories.

5. Loading theme rasters (grids) and accessory information to the modelling engine and user interface.

6. Interactively applying decision making preferences and perform aggregation by addition (with or without weighting).

7. Reviewing output from several treatments (scenarios) to establish areas that consistently satisfy decision needs.

8. Communicating results to clients - policy makers and/or the general public.

9. Optional repetition of components $2-8$ for a smaller region or regions identified as worthy by the first process.

\section{Application of ASSESS to Site Selection}

A site for a low-level and short-lived, intermediate-level radioactive waste repository is being sought in Australia. This project commenced in 1992 with the development of ASSESS as a scientifically based methodology with a functioning prototype for site selection that was and publicly accepted. To satisfy these requirements objectivity, transparency and the ability to involve the wider scientific community and the public was needed. In the geographical site selection context, objectivity was achieved by reviewing the whole Australian continent. This countered the NIMBY - Not in My Backyard response by an unbiased assessment of everyone's backyard. Objectivity in the selection criterion sense was established by using site selection criteria provided by an independent agency. Objectivity in system modelling was achieved by open statement of the modelling procedure and by enabling interactive review of all information so anyone could exert their preferences. Transparency of process was enabled by easy access to information both inside the ASSESS interface and through the provision of public discussion papers. The public discussion papers called for comment and suggestions on the methodology and its implementation.

Different interpretations of suitability were explored using the same or different information rated in different ways. Those areas that remained suitable despite numerous reinterpretations were considered more robust in both a spatial and a decision sense. These areas became the focus for selecting smaller regions. Because public and broader scientific involvement was inviled, other areas were also considered. The basis for their nomination was mainly because they were volunteered or because of a perceived compatible historical land use.

The best available regional information was then assembled and the scenario testing process repeated. The outcome was that some regions showed relatively suitable, spatially continuous large areas whereas others had only small or scattered areas. The preferred region for detailed field survey will be announced shortly and will involve a reassessment of the criteria using local knowledge. 


\section{CONCLUSION}

ASSESS applies site selection criteria to identify areas suitable for land use applications. The system works for whole continents, regions or small areas. The methodology has been extensively tested by public and scientific comment on the approach and its usefulness for site selection. As an effective land use and site selection decision support system it:

- integrates the user;

- draws from many social, economic and scientific disciplines;

- $\quad$ supports a ticred approach;

- retains functions and validity at various scales;

- provides clear, accessible documentation and has a transparent process;

- enables scenario flexibility, yet rigour in process modelling.

ASSESS achicves this by integrating GIS and DSS with a GUI for simple use where the user becomes an integral part of the system.

\section{REFERENCES}

Battey, M. and Xie, Y. (1994) Modelling inside GIS: Part 1. Model structures, exploratory data analysis and aggregation. Int. J. Geographic Information Systems, 8, 291 - 307.

Brown, J.R. and MacLeod, N.D. (1996) Integrating ecology into natural resource management policy. Environmental Management, 20, 289 - 96.

Gault, F.D., Hamilton, K.E., Hoffman, R.B. and McInnis, B.C. (1987) The design approach to socio-economic modelling. Futures, February, $3-25$.

Hopkins, L. (1977) Methods for generating land suitability maps: a comparative evaluation. J. Am. Inst. Planners, October, 386- 400.

Jankowski, P. (1995) Integrating geographical information systems and multicriteria decision making methods. Int. J. of Geographic Information Systems, 9, $251-73$.

McHarg, I.L. (1969) Design with nature. John Wiley \& Sons, Garden City, NJ.

Richards, M.D. (1992) Siting Industrial Facilities - lessons from the social science literature. U.S. Council for Energy Awareness.

Sprague, R.H. (1986) A framework for the development of decision support systems, in Decision Support Systems, Putting Theory into Practice (eds. R.H. Sprague and H. J. Watson), Prentice Hall International Inc., New Jersey.

Srinivasan, A. and Richards, J.A. (1993) Analysis of GIS spatial data using knowledge -based methods. Int. J. of Geographic Information Systems, 7, 479 -500 .

Stein, A., Staritsky, I., Bouma, J. and van Groenigen, J.W. (1995) Interactive GIS for environmental risk assessment. Int. J. Geographic Information Systems, 9 , $509-25$.

Watson, P.M. and Wadsworth, R.A. (1996) A computerised decision support system for rural policy formulation. Int. J. Geographic Information Systems, 4, $425-40$. 